\title{
Indinavir trough concentration as determinant of early nephrolithiasis in HIV-1- infected adults
}

\begin{abstract}
Authors
Fidéline Collin $(\mathrm{PharmD})^{1}$, Geneviève Chêne $(\mathrm{MD}, \mathrm{PhD})^{1}$, Sylvie $\operatorname{Retout}^{2}(\mathrm{PhD})$, Gilles Peytavin (PharmD, PhD) $)^{3}$, Dominique Salmon ${ }^{4}(\mathrm{MD}, \mathrm{PhD})$, Elisabeth $\operatorname{Bouvet}^{3}(\mathrm{MD}, \mathrm{PhD})$, François Raffi (MD, PhD) $)^{5}$, Rodolphe Garraffo (PharmD, PhD) ${ }^{6}$, France Mentré2 $(\mathrm{MD}$, PhD), Xavier Duval (MD, PhD) ${ }^{3}$ and the ANRS CO8 Aproco-Copilote Study Group.
\end{abstract}

\section{Affiliations}

${ }^{1}$ INSERM, U593, Bordeaux, F-33076, France ; ISPED, Univ Victor Segalen Bordeaux 2, ISPED Bordeaux, F-33076 France

${ }^{2}$ INSERM U738, Paris, F-75018, France; Département d'Epidemiologie, Biostatistique et Recherche Clinique, Hôpital Bichat-Claude Bernard, Paris, F-75018, France; Université Paris VII, Paris, F-75018 France.

${ }^{3}$ Hôpital Bichat-Claude Bernard, Paris, France

${ }^{4}$ Hôpital Cochin Tarnier, Faculté René Descartes, Paris, France

${ }^{5}$ Hôpital Hôtel Dieu, Nantes, France

${ }^{6}$ Hôpital Pasteur, Nice, France

\section{Corresponding author and reprints}

Geneviève Chêne

INSERM U 593 
Université Victor Segalen Bordeaux 2

146, rue Léo Saignat - case 11

33076 BORDEAUX Cedex

phone : +33557571257/fax : +33557571172

e-mail : Genevieve.Chene@isped.u-bordeaux2.fr

\section{Sources of financial support:}

Agence Nationale de Recherches sur le SIDA et les hépatites virales (ANRS, Action Coordonnée $n^{\circ} 7$ )

Collège des Universitaires de Maladies Infectieuses et Tropicales (CMIT, formerly APPIT),

Sidaction, Ensemble contre le Sida and associated pharmaceutical companies: Abbott, Boehringer-Ingelheim, Bristol-Myers Squibb, Glaxo- SmithKline, Merck Sharp and Dohme, Roche.

Number of pages: 28

Number of figures: 2

Number of tables: 2 


\section{ABSTRACT}

Indinavir plasma levels are associated with antiretroviral efficacy however few data is available regarding toxicity. We assessed the relationship between indinavir pharmacokinetic $(\mathrm{PK})$ characteristics and severe nephrolithiasis as well as other severe or serious adverse reactions (SAR). Patients included in the ANRS CO8 APROCOCOPILOTE cohort and receiving indinavir $800 \mathrm{mg}$ thrice daily as first line protease inhibitor, were eligible for this study. To be included in the analysis, their plasma sample at month 1 (M1) had to be available $(n=282)$ to estimate, using population PK modelling, indinavir PK characteristics, i.e. maximum $\left(\mathrm{C}_{\max }\right)$ and trough plasma $\left(\mathrm{C}_{\mathrm{res}}\right)$ concentrations, area under the curve (AUC) and observed/predicted concentrations ratio (CR). A Cox model was used to estimate the independent effect of $\mathrm{C}_{\max }, \mathrm{C}_{\mathrm{res}}$, $\mathrm{AUC}$ and $\mathrm{CR}$ on the hazard of severe nephrolithiasis and SAR. At M1, median $\mathrm{C}_{\max }$ was $6205 \mathrm{ng} / \mathrm{mL}, \mathrm{C}_{\text {res }}: 631 \mathrm{ng} / \mathrm{mL}$, AUC: 24242 ng.h/mL and CR: 0.6. After a median follow-up of 12 months, $11 \%$ of patients (30/282) had experienced at least one SAR among which 12 were nephrolithiasis. In the multivariate analyses, early high indinavir $\mathrm{C}_{\text {res }}$ (i.e. $\geq 1000 \mathrm{ng} / \mathrm{mL}$ at $\mathrm{M} 1$ ) was associated with a higher rate of severe nephrolithiasis ( $\mathrm{HR}=6.7 ; 95 \%$ confidence interval $=1.8-25.2 ; \mathrm{p}<0.01)$ and was also associated with a higher rate of all SAR but only when nephrolithiasis were included among those cases. Prospective and early indinavir $\mathrm{C}_{\text {res }}$ determination should be recommended in the patient's care management and dosage adjustments.

Keywords: Indinavir, plasma levels, nephrolithiasis, toxicity, pharmacokinetic. 


\section{INTRODUCTION}

One of the main drawbacks of Highly Active Antiretroviral Therapy (HAART) is toxicity, leading to treatment discontinuations and limitation of treatment options. Among baseline characteristics, high plasma HIV RNA, elevated aspartate animotransferase (AST), reduced creatinine clearance, positive hepatitis C-virus (HCV) antibodies or hepatitis B (HB) antigenemia, gender, age and HIV transmission group are considered as determinants of protease inhibitor $(\mathrm{PI})$ related toxicity $(1,2)$. Among other potential determinants, PI plasma levels have been less studied although the measurement of drug concentration, i.e. therapeutic drug monitoring (TDM), has shown a large interest in many diseases (3-5), to improve efficacy and minimize toxicity. Moreover, PIs are good candidates for TDM because of high inter-patient variability in plasma concentrations, binding to plasma proteins, P450 3A4 cytochrom metabolism, short half-life, drug-food and drug-drug interactions $(6,7)$ that may lead to inadequate PIs exposure among patients receiving the same dose.

Many studies in HIV-infected patients have previously focused on a relationship between concentration and effect, in terms of virological response (8-11), whereas toxicity was a secondary outcome. When adverse events have become a major problem in treated HIV-infected patients, data found in the literature show insufficient evidence to recommend a general therapeutic range, probably because only few databases have both appropriate pharmacokinetics and toxicity data available, like in the ANRS CO8 APROCOCOPILOTE cohort.

The aim of our analysis was to assess the relationship between indinavir individual PK characteristics, one month after initiating indinavir containing therapy, and severe 
nephrolithiasis or any severe or serious adverse reactions (SAR), occurring in the following year, among patients included in an observational cohort of patients starting HAART with a PI-containing regimen.

\section{PATIENTS AND METHODS}

APROCO-COPILOTE cohort is a prospective observational cohort study of 1281 HIV-1-infected patients, naive of PIs, enrolled at the initiation of a PI from May 1997 to June 1999, in 47 clinical centers in France, after giving written informed consent. The study was approved by the Paris-Cochin Ethics Committee.

Among patients included in the APROCO-COPILOTE cohort, $513(40.0 \%)$ have started their PI with indinavir $800 \mathrm{mg}$ three-times-daily. Because the first plasma concentration was measured at month 1 (M1), we have restricted the analysis to the 282 patients $(22.0 \%)$ who have not experienced any indinavir discontinuation, nor dosage adjustment, nor SAR before M1 and have had a proper recording of the time interval between intake of last dose and plasma sampling. To ensure that no major potential selection bias was induced, the rate of SAR and available characteristics at M1 were compared between the 282 patients included and other potentially eligible patients but without available indinavir sampling results $(\mathrm{n}=51)$.

At a random time between intake and plasma sampling, a single blood sample was collected at M1. Indinavir plasma concentration was measured using a validated highperformance liquid chromatography method $(12,13)$. The lower limit of quantification was 
$5 \mathrm{ng} / \mathrm{mL}$. The interday and intraday coefficients of variation of the assay were less than $11 \%$ and $8 \%$.

A one-compartment model with first-order absorption and elimination was used to describe the PK population parameters of indinavir as shown by Brendel et al (14) and used by Duval et al (11). A population analysis (15) was performed to estimate both the mean and the inter-individual variability of the PK parameters included in this model, i.e. the clearance $(\mathrm{CL})$ and the volume of distribution $(\mathrm{V})$, the absorption rate constant $(\mathrm{ka})$ being fixed to $0.49 \mathrm{~h}^{-1}$. From this population analysis, the individual parameters of the 282 patients were derived using Bayesian estimation (16). The population analysis and the Bayesian estimation was performed using the FOCE method of NONMEM version 5 (UCSF, San Fransisco, CA $)$. Maximum $\left(\mathrm{C}_{\max }\right)$ and trough $\left(\mathrm{C}_{\mathrm{res}}\right)$ plasma concentrations were then calculated according to a classical steady-state formulae for repeated oral dose:

$\mathrm{C}(\mathrm{t})=\frac{\text { Dose }}{V} \times \frac{k a}{\frac{C L}{V}-k a} \times\left[\frac{\exp (-k a \times t)}{1-\exp (-k a \times \tau)}-\frac{\exp \left(-\frac{C L}{V} \times t\right)}{1-\exp \left(-\frac{C L}{V} \times \tau\right)}\right]$

with $\mathrm{C}(\mathrm{t})$ being the plasma concentration versus time and $\tau$ the interval between two intakes (8 hours).

At steady state, area under the plasma curve up to $8 \mathrm{~h}$ after intake $\left(\mathrm{AUC}_{0-8 \mathrm{~h}}\right)$, was estimated by the Dose/CL ratio. The observed/predicted concentrations ratio (CR) was estimated by the ratio between the observed concentration and the predicted concentration at the same time using the mean population parameters estimated during the population analysis (10). 
In the APROCO-COPILOTE cohort, all SAR, defined as death, event threatening vital prognosis, event requiring an hospitalisation or an extension of hospitalisation, laboratory or clinical grade 3 or $4 \quad$ event (http://www.anrs.fr/index.php/article/articleview/1358/1/615), are prospectively collected. For each event, grade and causality assessment was first evaluated by the physician in charge of the patient and revised by a centralised Events Validation Committee, using the standardised definition of the National Agency for Research on AIDS and Viral Hepatitis (ANRS) (17). In a first analysis, only cases of nephrolithiasis among SAR related to indinavir occurring in the first year after initiating indinavir containing therapy, were taken into account because they are the most frequent and specific SAR related to indinavir use (18-23). Then, all SAR (including nephrolithiasis) and SAR excluding nephrolithiasis were studied in two secondary analyses. In all analyses, follow-up data were censored one month after first indinavir discontinuation or dose adjustment.

A Cox proportional hazards regression model was used to estimate the independent effect of the individual indinavir PK characteristics $\left(\mathrm{C}_{\mathrm{res}}, \mathrm{C}_{\max }, \mathrm{AUC}, \mathrm{CR}\right)$ on the risk of first nephrolithiasis or SAR occurrence (depending on the analysis performed), and adjusted for potential other risk factors : age, gender $(24,25)$, body weight (26) or body mass index (BMI) (18) or body surface area (BSA) as estimated by the Gehan and George formula (27), alanine aminotransferase (ALT) and AST (28), HCV antibodies and HBs antigenemia serologic status (25), creatinine clearance as estimated by the Cockcroft-Gault formula (29), plasma HIV RNA, CD4+ T-lymphocyte count and adherence to indinavir, all assessed at M1. Assessment of adherence was made by a self-administrated questionnaire. 
A patient was considered as fully adherent at the M1 visit if he/she declared that he/she had totally complied with his/her indinavir prescription during the 7 days before M1.

Quantitative variables with clinically relevant thresholds were analysed as categorical variables, i.e. CD4+ cell count categorised as $\leq 200,200$ to 500 and $>500 / \mathrm{mm}^{3}$, BMI as $<19,19$ to 25 and $\geq 25 \mathrm{~kg} / \mathrm{m}^{2}$. Regarding other quantitative variables, quartiles, median or thresholds suggested by the variable distribution, were considered. The choice of a potential categorisation for each variable was based on the Akaike criterion (AIC) of the corresponding univariate analysis, the model with the lowest AIC was chosen. In case of similar AIC for at least two models, the most relevant categorisation for clinical practice was retained.

Variables were included in the initial multivariate Cox regression model if they were associated with nephrolithiasis or SAR in each univariate analysis separately with a $\mathrm{p}<0.25$. Reduced models resulted from stepwise selection retaining only variables associated with nephrolithiasis or SAR at the 0.05 significance level. In the final multivariate model, a $\chi^{2}$ test using the minimum p-value approach was used for all categorised variables associated with nephrolithiasis or SAR, in order to choose the more discriminating threshold among those best separating patients with nephrolithiasis or SAR from patients without (30). To avoid biased relative risk, it was followed by a cross validation (31). SAS software (version 8.2 ; SAS Institute Inc, Cary, NC, USA) was used for statistical analysis.

Moreover, as the model assumed that censored follow-up was not informative, i.e. not related to toxicity, a robustness analysis was performed to check this hypothesis. For 
this purpose, toxicity was defined, depending on the analysis performed, as nephrolithiasis only or overall SAR, indinavir discontinuations more than 30 consecutive days for any adverse event or for nephrolithiasis only and dose adjustments.

\section{RESULTS}

Our analysis included mainly men (78\%) in their forties (Table I). The median indinavir concentration was $2200 \mathrm{ng} / \mathrm{mL}$ (Interquartile range (IQR): 242-6072 ng/mL) (Figure 1). The median sampling time interval was $3.3 \mathrm{~h}$ (IQR: 2.0-5.8 h) after dose intake. The median follow-up was 12 months. Thirty SAR occurred in the first year after initiating indinavir containing therapy. Twelve cases were nephrolithiasis (incidence density: 5\% patient-years) whereas the 18 others were mainly hepatic cytolysis $(n=6)$, hyperglycemia/diabetes mellitus $(n=3)$ and death (one unexplained respiratory distress and one pancreatitis with lactic acidosis). The median time until the occurrence of the first nephrolithiasis was 5.5 months (IQR: 3.3-7.7 months).

The rate of SAR did not differ between patients with $(\mathrm{n}=282)$ and without indinavir sampling results $(\mathrm{n}=51)(\mathrm{p}=0.81)$, neither their characteristics assessed at M1.

The mean and the inter-individual variability of the PK parameters included in the model, i.e. the clearance (CL) and the volume of distribution (V), according to the

population analysis were respectively for CL : $32.1 \mathrm{~L} / \mathrm{h}$ (standard error (SE): $5.7 \%$ ) and 34\% (SE: $52.4 \%$ ); for V: 58.5 L (SE: $13.5 \%$ ) and 227\% (SE: 31\%). 
Nine of the 12 patients with nephrolithiasis were fully adherent (data missing for the 3 others) as compared to 214 of 270 patients without nephrolithiasis. In the univariate analysis, only estimated $\mathrm{C}_{\text {res }}, \mathrm{C}_{\max }, \mathrm{AUC}$ and $\mathrm{CR}$ as well as plasma HIV RNA and age remained associated with a higher rate of nephrolithiasis, according to the best cut-off when categorised (Table II). Nephrolithiasis occurred in 9 of the 88 patients having a $\mathrm{C}_{\text {res }}$ above $1000 \mathrm{ng} / \mathrm{mL}$ at $\mathrm{M} 1$ and the probability of developing a first nephrolithiasis at month 12 (M12) was $14 \%$ when $\mathrm{C}_{\text {res }}$ was above $1000 \mathrm{ng} / \mathrm{mL}$ at $\mathrm{M} 1$ versus $2 \%$ when $\mathrm{C}_{\text {res }}$ was under $1000 \mathrm{ng} / \mathrm{mL}$ (Figure 2). In the multivariate analysis (Table II), a $\mathrm{C}_{\text {res }}$ plasma concentration above $1000 \mathrm{ng} / \mathrm{mL}$ at $\mathrm{M} 1$ remained the only independent determinant of a higher rate of nephrolithiasis $\left(\mathrm{HR}=6.7 ; 95 \%\right.$ confidence interval $\left.(\mathrm{CI})=1.8-25.2 ; \mathrm{p}<10^{-2}\right)$. The approach of minimum p-value associated to a cross validation confirmed the cut-off of $\mathrm{C}_{\mathrm{res}}$ of 1000 $\mathrm{ng} / \mathrm{mL}$ and an association between a $\mathrm{C}_{\mathrm{res}}$ above $1000 \mathrm{ng} / \mathrm{mL}$ with a higher rate of nephrolithiasis $(\mathrm{HR}=4.1 ; 95 \% \mathrm{CI}=1.3-12.8 ; \mathrm{p}=0.02)$.

In the robustness analysis censoring indinavir discontinuations for nephrolithiasis and dose adjustments: a $\mathrm{C}_{\text {res }}$ above $1000 \mathrm{ng} / \mathrm{mL}$ still remained independently associated with a higher rate of nephrolithiasis: $\mathrm{HR}=3.9(95 \% \mathrm{CI}=1.5-10.0 ; \mathrm{p}=0.005)$, indicating that the impact of informative censoring was not large enough to modify the initial conclusions.

The median time until the occurrence of the first SAR was 4.5 months (IQR: 2.7-7.5 months). The probability of developing a first SAR at M12 was $21.7 \%$ when $\mathrm{C}_{\text {res }}$ was above $1000 \mathrm{ng} / \mathrm{mL}$ at $\mathrm{M} 1$ versus $8.2 \%$ when $\mathrm{C}_{\text {res }}$ was under $1000 \mathrm{ng} / \mathrm{mL}$. When any SAR were analysed, in a multivariate model, the following variables assessed at M1 were independently associated with a higher hazard of SAR: $\mathrm{C}_{\text {res }}$ above $1000 \mathrm{ng} / \mathrm{mL}(\mathrm{HR}=3.3$; 
95\% CI=1.1-10.1; $\mathrm{p}<0.05$ ), plasma HIV RNA ( $\mathrm{HR}=0.2$ for each lower $1 \log _{10}$ copies $/ \mathrm{mL}$; $95 \% \mathrm{CI}=0.06-0.8 ; \mathrm{p}<0.05)$ and estimated creatinine clearance under $70 \mathrm{~mL} / \mathrm{min}(\mathrm{HR}=2.7$; $95 \% \mathrm{CI}=1.0-7.3 ; \mathrm{p}=0.05)$. In the robustness analysis, a $\mathrm{C}_{\mathrm{res}}$ above $1000 \mathrm{ng} / \mathrm{mL}$ was not associated with a higher rate of SAR: $\mathrm{HR}=1.7(95 \% \mathrm{CI}=0.8-3.5 ; \mathrm{p}=0.13)$.

Unlike the two primary analyses, no significative association with $\mathrm{C}_{\mathrm{res}}(\mathrm{p}=0.37)$ or other indinavir PK characteristics was shown, when the analysis considered as outcomes only the 18 SAR that were not nephrolithiasis.

\section{DISCUSSION}

In this population of initially PI-naïve patients, a $C_{\text {res }}$ of indinavir above 1000 $\mathrm{ng} / \mathrm{mL}$, assessed at the steady state of HAART, was associated with a sevenfold higher rate of nephrolithiasis in the following year. This result potentially justifies Therapeutic Drug Monitoring during indinavir containing therapy.

Whereas the APROCO-COPILOTE cohort has included 513 unselected HIVinfected patients starting indinavir containing therapy, the present analysis was restricted to a sub-group of 282 patients. Although we acknowledge a potential lack of power, a selection bias is unlikely as the rate of SAR was similar in those patients with available plasma sampling and in those without. Therefore, we believe that indinavir $\mathrm{C}_{\mathrm{res}}$ at the proposed threshold is strongly associated with nephrolithiasis. Non compliance with water intake or hot environmental temperature are known to be associated with higher incidence of nephrolithiasis $(21,28,32)$, but were not available in our database. For instance, in a hot 
climate, excessive sweating leading to low urinary volume, may itself predispose to nephrolithiasis, because of a phenomenon of dehydration. In our study, as 7 on the 12 nephrolithiasis occurred between May and September, we believed that hot weather might have contributed to the occurrence of nephrolithiasis in patients having basal high indinavir plasma level. Even if food intake was not recorded in our database, we believe that a major bias due to food intake is unlikely. In the cohort, the current practice for the patients was to be on fasting conditions when they were sampled in the morning. If they already had their breakfast, we can assume that it was most often a continental breakfast, unlikely to be rich in fat. However, we did not record the specific information on fasting conditions in these patients and cannot take this into account in the analysis precisely. Finally, to our knowledge, indinavir pharmacokinetic characteristics are not so much affected by food intake, conversely to a drug such as nelfinavir. Moreover, drugs that might interact with indinavir (i.e. ketoconazole, rifabutine, rifampicine) have been rarely prescribed in this study.

Only few previous studies have shown a relationship between higher plasma PI concentration and higher toxicity $(20,33-35)$. Two of them involved indinavir containing therapy but they had limitations regarding the collection of toxicity data and plasma sample as well as statistical analysis. Unlike Solas et al and Dieleman et al who analysed data from less than $70 \mathrm{HIV}$-infected patients, the present study was based on a large prospective cohort, thus improving statistical power. Moreover, our estimation of any relationship between SAR and PK characteristics such as $\mathrm{C}_{\mathrm{res}}, \mathrm{C}_{\max }$, AUC and $\mathrm{CR}$ is based on prospective follow-up data, allowing the description of a temporal relationship which increases the potential for evidence based conclusions. Dieleman et al have used a case- 
control design, comparing 17 patients with nephrolithiasis to an historical control group of 14 patients. Morevover, in their study, indinavir plasma levels were measured while nephrolithiasis had already occurred so that concentrations are not tested as prospective factors and the temporal relationship between concentrations and nephrolithiasis can not be properly assessed. Solas et al have shown that, in 63 patients receiving ritonavir/indinavir (100/800mg) twice daily, higher indinavir $\mathrm{C}_{\text {res }}$ was associated with higher rate of any toxicity. After initiation of ritonavir/indinavir regimen and sometimes after dose adjustment, indinavir $\mathrm{C}_{\mathrm{res}}$ was assessed and compared between patients with and without occurrence of toxicity. Toxicity including nephrolithiasis occurred more frequently when $\mathrm{C}_{\text {res }}$ was above $500 \mathrm{ng} / \mathrm{mL}$. Contrary to the present study, no specific approach was used to validate this cut-off. Even if the cut-off value of $1000 \mathrm{ng} / \mathrm{mL}$, reported in our study, seems high compared with the range of $150 \mathrm{ng} / \mathrm{mL}$ to $500 \mathrm{ng} / \mathrm{mL}$ reported by others $(6,7,23,33)$, it may be explained by the modelling estimate of $\mathrm{C}_{\mathrm{res}}$, precisely 8 hours after last intake. However, it is rarely reached in clinical practice since treatment is given the preceding evening. Knowing the short indinavir half-life, plasma concentrations are twice lower every 90 minutes, leading to lower observed $\mathrm{C}_{\text {res }}$ if one does take into account the time interval between last intake and sampling.

Although we acknowledge that indinavir is rarely used without ritonavir in the actual clinical practice, we believe that the design of the present study is valuable for other PI-containing therapies. As already underlined, the prospective observational cohort design of the present study, the population PK modelling and the cut-off determination by a formal strategy are valuable tools that can be recommended for further toxicity-plasma levels 
relationship studies. It also could give complementary data on potential indinavir cut-off in patients using ritonavir-boosted indinavir combination, since it has been well established that ritonavir considerably boosted indinavir $\mathrm{C}_{\text {res }}(38)$. This seems all the more important to early monitor indinavir concentration to avoid indinavir $\mathrm{C}_{\text {res }}$ above $1000 \mathrm{ng} / \mathrm{mL}$ as Brendel et al have recently shown in patients receiving ritonavir/indinavir $(100 / 800 \mathrm{mg})$ twice daily that, median indinavir trough concentrations ranged from $700 \mathrm{ng} / \mathrm{mL}$ to $1250 \mathrm{ng} / \mathrm{mL}$ (14).

No consensus exists on the therapeutic range of indinavir concentration and data found in the literature show insufficient evidence to recommend a general therapeutic range (36), surely because of a lack of available toxicity and PK data. Yet, several studies (8-10, 37) have already shown that low PIs (or non-nucleoside reverse transcriptase inhibitor) plasma concentrations are associated with virologic failure. When Duval et al have shown that the most discriminating cut-off associated with virologic response was $194 \mathrm{ng} / \mathrm{mL}$ (11), in a population of fully adherent patients receiving indinavir $800 \mathrm{mg}$ tid at M4 from the APROCO/COPILOTE cohort and using a similar PK modelling, our results demonstrate that $\mathrm{C}_{\text {res }}$ plasma concentration of indinavir above $1000 \mathrm{ng} / \mathrm{mL}$ is associated with a higher risk of nephrolithiasis occurrence. We may so suggest that the optimal therapeutic range of indinavir $\mathrm{C}_{\text {res }}$ could be $200 \mathrm{ng} / \mathrm{mL}$ to $1000 \mathrm{ng} / \mathrm{mL}$. On the basis of these data, prospective and early assessments of indinavir $\mathrm{C}_{\text {res }}$ through therapeutic drug monitoring might be justified to allow dosage adjustment, while maintaining indinavir levels above efficacy threshold. 


\section{ACKNOWLEDGEMENTS}

The authors thank all patients and investigators in clinical sites (see Appendix). We also thank Rodolphe Thiebaut for statistical support, as well as Audrey Taïeb and Gwendoline Poizat.

\section{CONFLICT OF INTEREST STATEMENT}

Drs E. Bouvet, F. Collin, X. Duval, R. Garraffo, F. Mentre, G. Peytavin, F. Raffi, S. Retout and D. Salmon have not commercial or other associations that might pose a conflict of interest. Dr G. Chêne has received grant support and lecture fees from Bristol-Myers Squibb, Gilead, Glaxo- SmithKline, Roche and Aventis. 


\section{REFERENCES}

1. Duval X, Journot V, Leport C, et al. Incidence and determinants of severe adverse reaction in a prospective cohort of HIV infected adults started on a protease inhibitor-containing therapy. Clin Infect Dis 2004;39:248-55.

2. Bonfanti P, Ricci E, Landonio S, et al. Predictors of protease inhibitor-associated adverse events. Biomed Pharmacother 2001;55:321-3.

3. Abad-Santos F, Carcas AJ, Ibanez C, et al. Digoxin level and clinical manifestations as determinants in the diagnosis of digoxin toxicity. Ther Drug Monit 2000;22:1638.

4. McMaster P, Mirza DF, Ismail T, et al. Therapeutic drug monitoring of tacrolimus in clinical transplantation. Ther Drug Monit 1995;17:602-5.

5. Lyass O, Uziely B, Ben-Yosef R, et al. Correlation of toxicity with pharmacokinetics of pegylated liposomal doxorubicin (Doxil) in metastatic breast carcinoma. Cancer 2000;89:1037-47.

6. Merck, Co.Inc. Crixivan (indinavir sulfate) product monograph. West Point, Pasadena 1997.

7. Murphy RL, Sommadossi JP, Lamson M, et al. Antiviral effect and pharmacokinetic interaction between nevirapine and indinavir in persons infected with human immunodeficiency virus type 1. J Infect Dis 1999;179:1116-23.

8. Durant J, Clevenbergh P, Garraffo R, et al. Importance of protease inhibitor plasma levels in HIV-infected patients treated with genotypic-guided therapy: pharmacological data from the Viradapt Study. Aids 2000;14:1333-9. 
9. Acosta EP, Henry K, Baken L, et al. Indinavir concentrations and antiviral effect. Pharmacotherapy 1999;19:708-12.

10. Burger DM, Hugen PW, Aarnoutse RE, et al. Treatment failure of nelfinavircontaining triple therapy can largely be explained by low nelfinavir plasma concentrations. Ther Drug Monit 2003;25:73-80.

11. Duval X, Mentre F, Lamotte C, et al. Indinavir plasma concentration and adherence score are codeterminant of early virologic response in HIV-infected patients of the APROCO cohort. Ther Drug Monit 2005;27:63-70.

12. Woolf E, Au T, Haddix H, et al. Determination of L-735 524, an human immunodeficiency virus protease inhibitor, in human plasma and urine via highperformance liquid chromatography with column switching. J Chromatogr A $1995 ; 692: 45-52$.

13. Aymard G, Legrand M, Trichereau N, et al. Determination of twelve antiretroviral agents in human plasma sample using reversed-phase high-performance liquid chromatography. J Chromatogr B Biomed Sci Appl 2000;744:227-40.

14. Brendel K, Legrand M, Taburet AM, et al. Population pharmacokinetic analysis of indinavir in HIV-infected patient treated with a stable antiretroviral therapy. Fundam Clin Pharmacol 2005;19:373-83.

15. Mandema J, P.G. Welling, and F.L.S. Tse. Population pharmacokinetics and pharmacodynamics, in Pharmacokinetics: regulatory, industrial, academics perspectives. Library of congress: New-York 1995:411-449.

16. Racine-Poon A, Wakefield J. Statistical methods for population pharmacokinetic modelling. Stat Methods Med Res 1998;7:63-84. 
17. Clinical safety data management : definitions and standards for expedited reporting. fed regist 1995;60:11284-11287.

18. Boubaker K, Sudre P, Bally F, et al. Changes in renal function associated with indinavir. Aids 1998;12:F249-54.

19. Brodie SB, Keller MJ, Ewenstein BM, et al. Variation in incidence of indinavirassociated nephrolithiasis among HIV-positive patients. Aids 1998;12:2433-7.

20. Dieleman JP, Gyssens IC, van der Ende ME, et al. Urological complaints in relation to indinavir plasma concentrations in HIV-infected patients. Aids 1999;13:473-8.

21. Flexner C. HIV-protease inhibitors. N Engl J Med 1998;338:1281-92.

22. Kopp JB, Miller KD, Mican JA, et al. Crystalluria and urinary tract abnormalities associated with indinavir. Ann Intern Med 1997;127:119-25.

23. Plosker GL NS. Indinavir : a review of its use in the management of HIV infection. Drugs 1999;58:1165-203.

24. Burger DM, Siebers MC, Hugen PW, et al. Pharmacokinetic variability caused by gender: do women have higher indinavir exposure than men? J Acquir Immune Defic Syndr 2002;29:101-2.

25. Bonfanti P, Valsecchi L, Parazzini F, et al. Incidence of adverse reactions in HIV patients treated with protease inhibitors: a cohort study. Coordinamento Italiano Studio Allergia e Infezione da HIV (CISAI) Group. J Acquir Immune Defic Syndr 2000;23:236-45.

26. Kirk O, Gerstoft J, Pedersen C, et al. Low body weight and type of protease inhibitor predict discontinuation and treatment-limiting adverse drug reactions 
among HIV-infected patients starting a protease inhibitor regimen: consistent results from a randomized trial and an observational cohort. HIV Med 2001;2:43-51.

27. Gehan EA, George SL. Estimation of human body surface area from height and weight. Cancer Chemother Rep 1970;54:225-35.

28. Carr A, Cooper D. Adverse effects of antiretroviral therapy. Lancet 2000;356:142330.

29. Cockcroft DW, Gault MH. Prediction of creatinine clearance from serum creatinine. Nephron 1976;16:31-41.

30. Duval X, Peytavin G, Albert I, et al. Determination of indinavir and nelfinavir trough plasma concentration efficacy thresholds according to virological response in HIV-infected patients. HIV Med 2004;5:307-13.

31. Mazumdar M, Smith A, Bacik J. Methods for categorizing a prognostic variable in a multivariable setting. Stat Med 2003;22:559-71.

32. Martinez E, Leguizamon M, Mallolas $\mathrm{J}$, et al. Influence of environmental temperature on incidence of indinavir-related nephrolithiasis. Clin Infect Dis 1999;29:422-5.

33. Solas C, Basso S, Poizot-Martin I, et al. High indinavir Cmin is associated with higher toxicity in patients on indinavir-ritonavir $800 / 100 \mathrm{mg}$ twice-daily regimen. $\mathrm{J}$ Acquir Immune Defic Syndr 2002;29:374-7.

34. Gatti G, Di Biagio A, Casazza R, et al. The relationship between ritonavir plasma levels and side-effects: implications for therapeutic drug monitoring. Aids 1999;13:2083-9. 
35. Khoo S, Gibbons S, Back D. Therapeutic drug monitoring as a tool in treating HIV infection. AIDS 2001;15 (suppl 5):S171-S181.

36. Rayner CR, Galbraith KJ, Marriott JL, et al. A critical evaluation of the therapeutic range of indinavir. Ann Pharmacother 2002;36:1230-7.

37. Marzolini C, Telenti A, Decosterd LA, et al. Efavirenz plasma levels can predict treatment failure and central nervous system side effects in HIV-1-infected patients. Aids 2001;15:71-5.

38. Burger D, Hugen P, Reiss $\mathrm{P}$, et al. Therapeutic drug monitoring of nelfinavir and indinavir in treatment-naive HIV-1-infected individuals. Aids 2003;17:1157-65. 


\section{APPENDIX}

\section{APROCO-COPILOTE Study Group}

\section{Scientific Committee:}

Steering Committee: Principal Investigators: C. Leport, F. Raffi, Methodology: G. Chêne, R. Salamon, Social Sciences: J-P. Moatti, J. Pierret, B. Spire, Virology: F. Brun-Vézinet, H. Fleury, B. Masquelier, Pharmacology: G. Peytavin, R. Garraffo.

Other members: D. Costagliola, P. Dellamonica, C. Katlama, L. Meyer, M. Morin, D. Salmon, A. Sobel.

Events Validation Committee: L. Cuzin, M. Dupon, X. Duval, V. Le Moing, B. Marchou, T. May, P. Morlat, C. Rabaud, A. Waldner-Combernoux.

Project coordination: F. Collin.

Observers: JF. Delfraissy, J. Dormon, P. Bursachi, M. Garré, JL. Vildé.

Clinical Research Group Coordinators: V. Le Moing, C. Lewden.

\section{Data monitoring and statistical analysis:}

C. Alfaro, F. Alkaied, C. Barennes, S. Boucherit, AD. Bouhnik, C. Brunet-François, MP. Carrieri, M. Courcoul, F. Couturier, JL. Ecobichon, M. François, L. Iordache, V. Journot, P. Kurkdji, R. Lassalle, E. Lootvoet, J.P. Legrand, E. Pereira, M. Préau, C. Protopopescu, J. Surzyn, A. Taïeb, F. Tourteau, V. Villes, H. Zouari. 


\section{Promotion:}

Agence Nationale de Recherches sur le SIDA et les hépatites virales (ANRS, Action Coordonnée $n^{\circ} 7$ )

\section{Other supports:}

Collège des Universitaires de Maladies Infectieuses et Tropicales (CMIT ex APPIT),

Sidaction Ensemble contre le Sida and associated pharmaceutical companies: Abbott, Boehringer-Ingelheim, Bristol-Myers Squibb, Glaxo- SmithKline, Merck Sharp and Dohme, Roche.

\section{Clinical Centers (coordinators):}

Amiens (Pr JL. Schmit), Angers (Dr JM. Chennebault), Belfort (Dr JP. Faller), Besançon (Pr JL. Dupond, Dr JM. Estavoyer,, Pr P. Humbert), Bobigny (Pr A. Krivitzky), Bordeaux (Pr M. Dupon, Pr Longy-Boursier, Pr P. Morlat, Pr JM. Ragnaud), Bourg-en-Bresse (Dr P. Granier), Brest (Pr M. Garré), Caen (Pr R. Verdon), Compiègne (Dr Y. Domart), Corbeil Essonnes (Dr A. Devidas), Créteil (Pr A. Sobel), Dijon (Pr H. Portier), Garches (Pr C. Perronne), Lagny (Dr P. Lagarde), Libourne (Dr J. Ceccaldi), Lyon (Pr D. Peyramond), Meaux (Dr C. Allard), Montpellier (Pr J. Reynes), Nancy (Pr T. May), Nantes (Pr F. Raffi), Nice (Pr JP. Cassuto, Pr P. Dellamonica), Orléans (Dr P. Arsac), Paris (Pr E. Bouvet, Pr F. Bricaire, Pr P. Bergmann, Pr J. Cabane, Dr G. Cessot, Pr P.M. Girard, Pr L. Guillevin, Pr C. Leport, Pr S. Herson, Pr MC Meyohas, Pr J.M. Molina, Pr G. Pialoux, Pr D. Salmon), Poitiers (Pr B. Becq-Giraudon), Reims (Pr R. Jaussaud), Rennes (Pr C. Michelet), Saint- 
Etienne (Pr F. Lucht), Saint-Mandé (Pr T. Debord), Strasbourg (Pr JM. Lang), Toulon (Dr JP. De Jaureguiberry), Toulouse (Pr B. Marchou), Tours (Pr JM Besnier). 


\section{FIGURES LEGENDS}

Figure 1. Observed plasma indinavir concentrations (dots) versus time and predicted concentrations using mean population parameters of indinavir (solid line), ANRS CO8 APROCO-COPILOTE sub-study (n=282), 1997-2000.

Figure 2. Cumulative probability of nephrolithiasis, estimated by the Kaplan-Meier

method, according to $\mathrm{C}_{\text {res }}$ : $\mathrm{C}_{\text {res }} \geq 1000 \mathrm{ng} / \mathrm{mL}$ (bold line) versus $\mathrm{C}_{\text {res }}<1000 \mathrm{ng} / \mathrm{mL}$, ANRS CO8 APROCO-COPILOTE sub-study (n=282), 1997-2000. 
Table I. Characteristics of the 282 patients included in the analysis, one month after initiating an indinavir containing therapy, ANRS CO8 APROCO-COPILOTE sub-study, 1997-2000.

\begin{tabular}{lcc}
\hline Characteristic No (\%) of patients or median value (IQR) \\
\hline Age (year) & 37.6 & $(32.7-45.6)$ \\
Male sex & 219 & $(77.7)$ \\
Body weight $(\mathrm{kg})$ & 67.0 \\
Body Mass Index $\left(\mathrm{kg} / \mathrm{m}^{2}\right)$ & 22.5 \\
Body Surface Area $\left(\mathrm{m}^{2}\right)$ & 1.8 \\
HIV transmission category & 119 \\
Man who has sex with men & 45 \\
Injection drug use & 90 \\
Sex between men and women & 10 \\
Haemophilia/transfusion & 18 \\
Unknown & $23.74 .0)$ \\
CDC stage C & 25.0 \\
Plasma HIV RNA (log 10 copies/mL) \\
CD4 ${ }^{+}$cell count (cells/mm ${ }^{3}$ ) \\
ALT (UI/L)
\end{tabular}


Positive HBs antigenemia

Positive HCV antibodies

Creatinine clearance $(\mathrm{mL} / \mathrm{min})$

indinavir pharmacokinetic characteristics

$\mathrm{C}_{\max }(\mathrm{ng} / \mathrm{mL})$

$\mathrm{C}_{\text {res }}(\mathrm{ng} / \mathrm{mL})$

AUC (ng.h/mL)

CR

Adherence scores

Low/mild

18

223

631

24242

0.6

(4874-7 104)

(384-1 270)

(22948-26217)

Full

NRTIs cumulated exposition in months

zidovudine

lamivudine

stavudine

didanosine

zalcitabine
14.8

6.0

4.8

10.3

(12.2)

12.3 
Table II. Occurrence of nephrolithiasis in HIV-1-infected patients, in the year after initiating an indinavir containing therapy, ANRS CO8 APROCO-COPILOTE sub-study (n=282), 1997-2000.

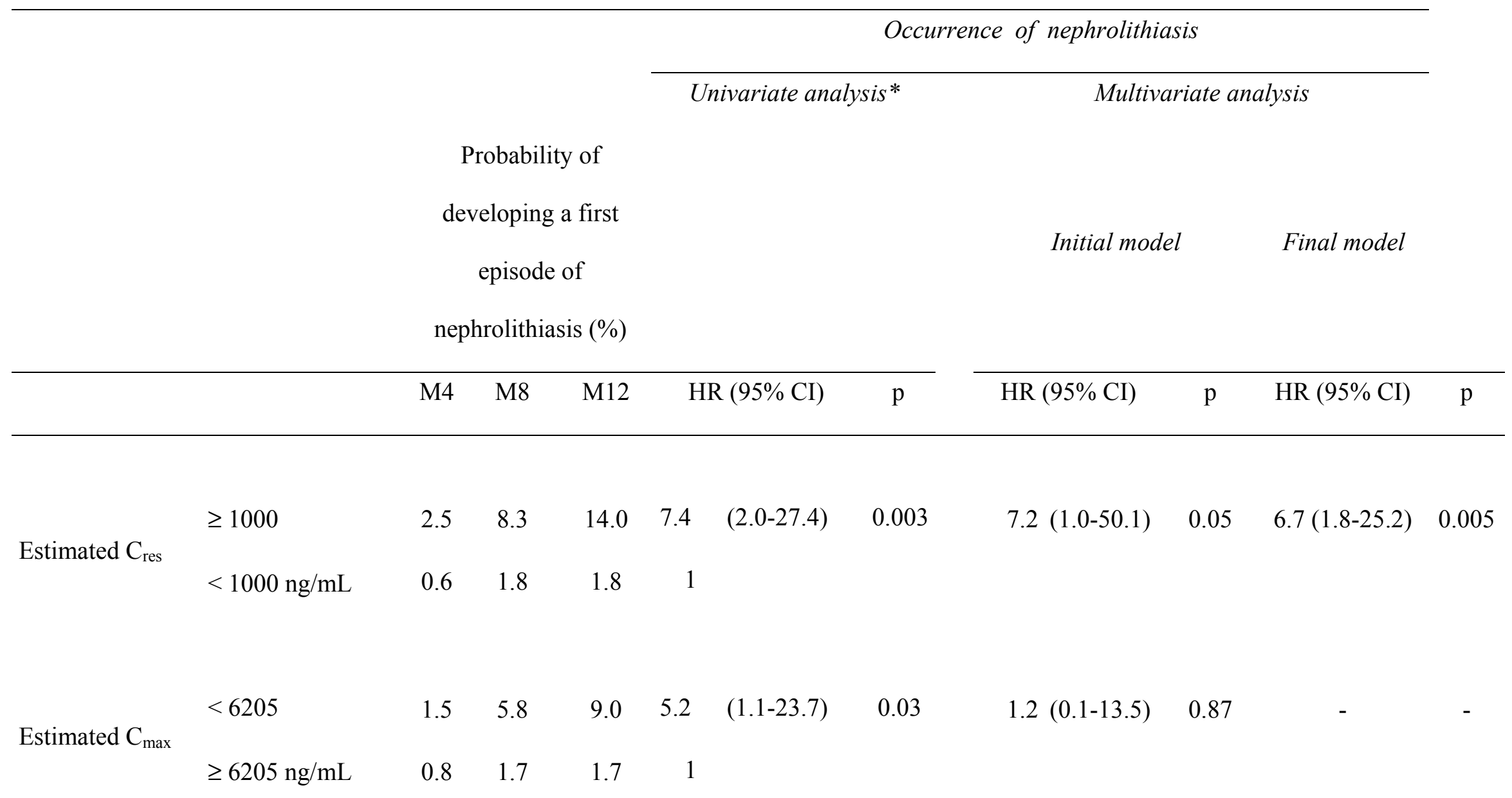




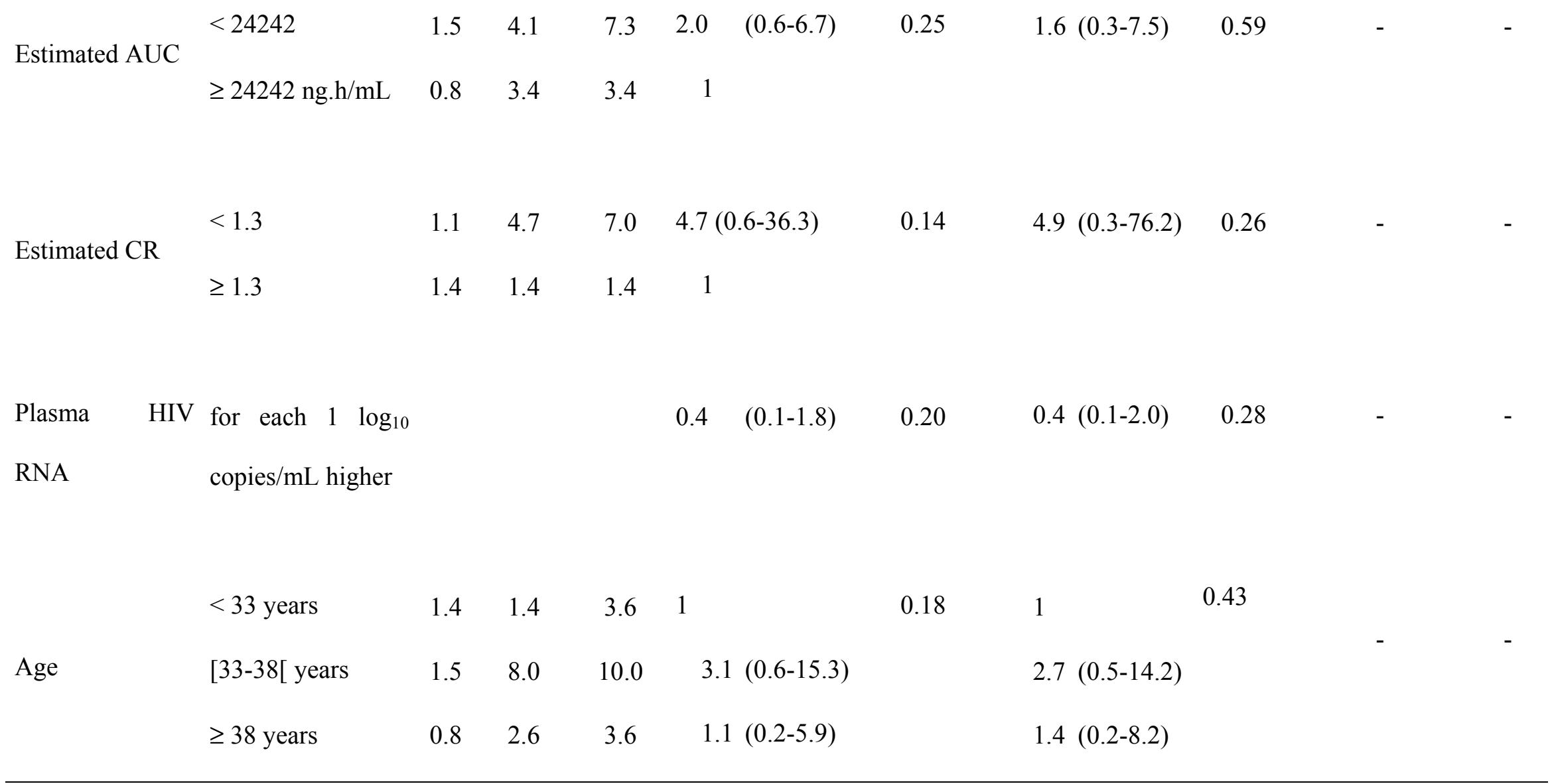

* Only variables associated with nephrolithiasis in univariate analyses with $\mathrm{p}<0.25$ are listed in this table.

M4, M8 and M12: 4, 8 and 12 months after initiating indinavir containing therapy, respectively; HR = Hazard Ratio ; CI = confidence interval 


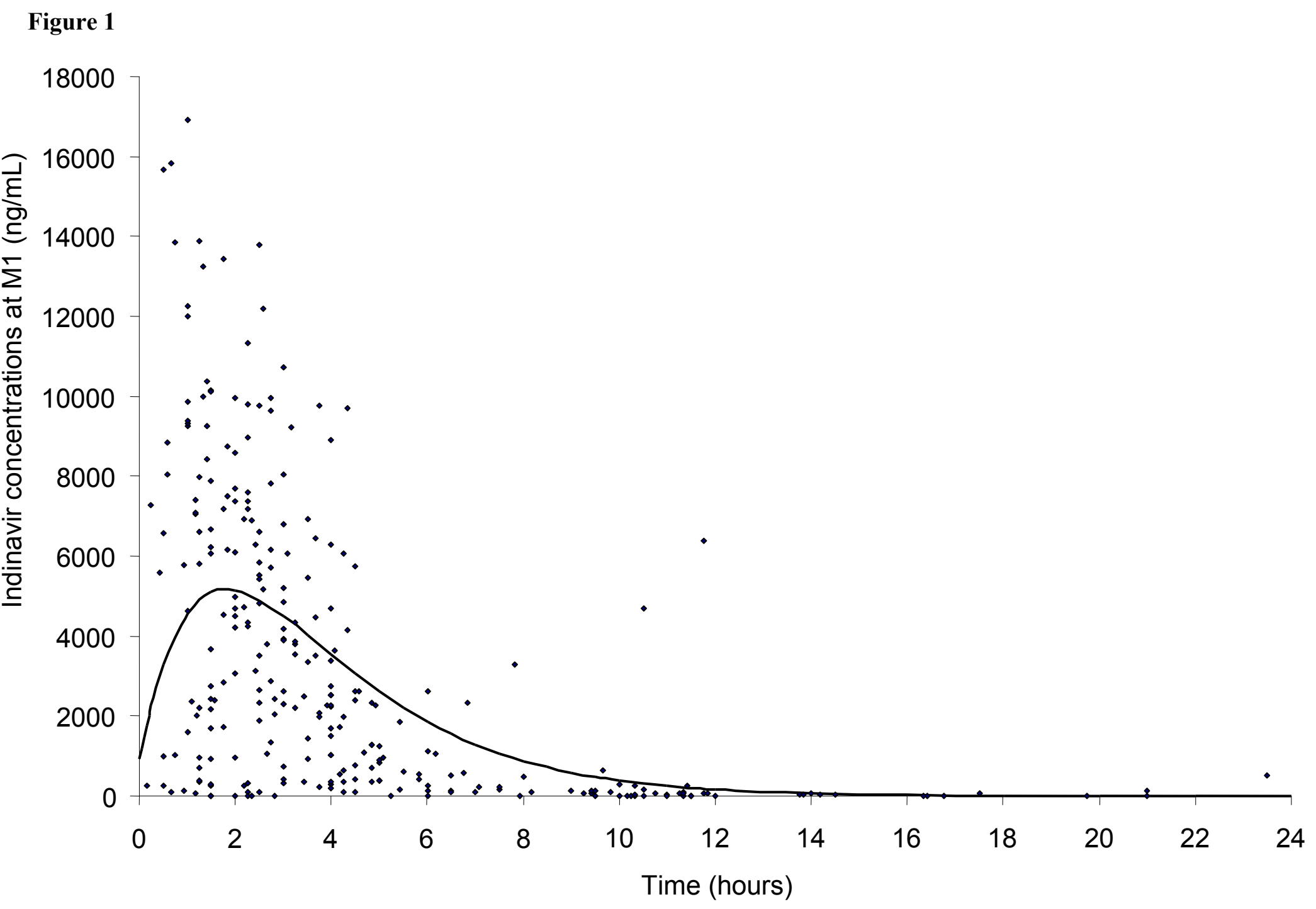


Figure 2

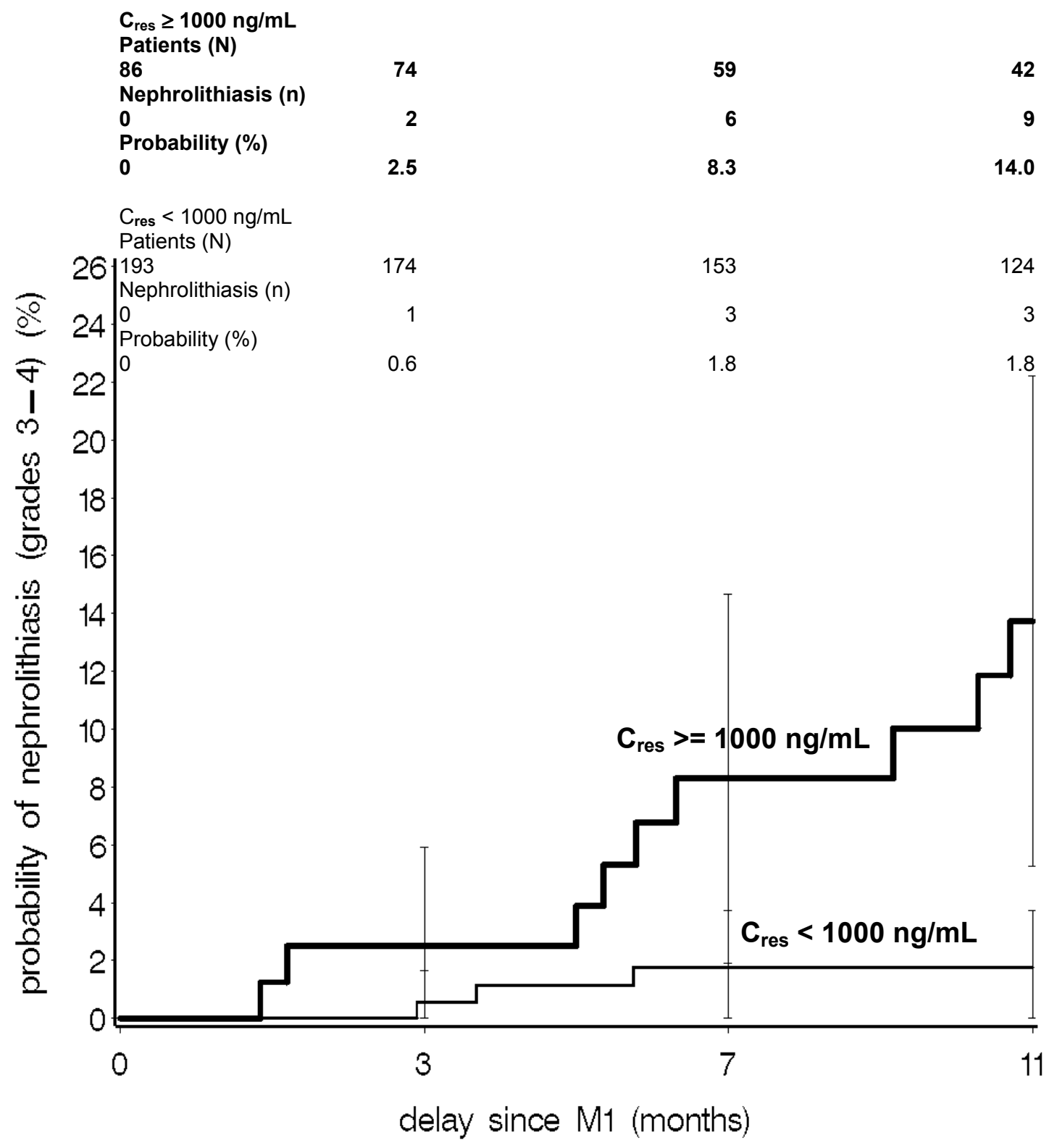

